\title{
When do I get to say we?
}

\author{
Tamsin Meaney \\ tamsin.meaney@hib.no \\ Faculty of Education, Bergen University College
}

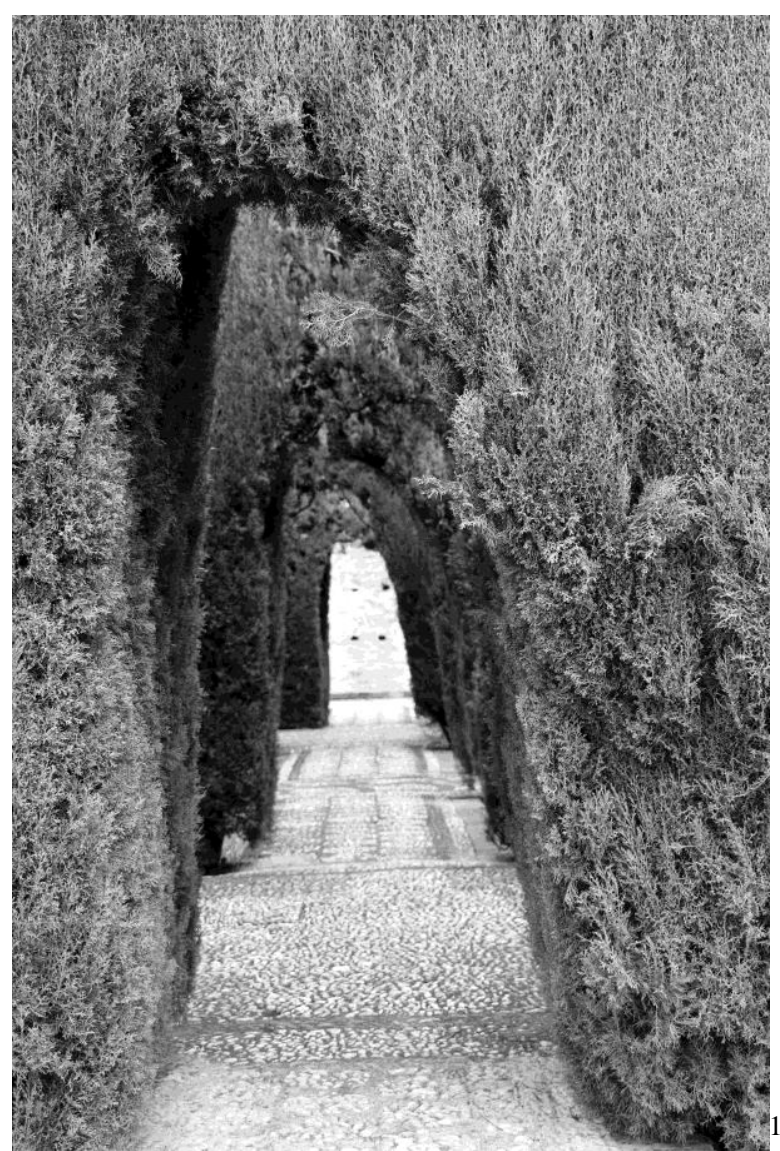

"We couldn't say what you just said", he told me at a conference ${ }^{2}$

Then, it seemed okay to talk for him, although it wasn't my intention.

My aim had been for those whose first language I share

To hear the world differently, so privilege could be challenged

Yet uncertainty tightened around me when I remembered this scene

\footnotetext{
${ }^{1}$ The photos were taken in Granada which had once had a thriving multicultural community under Muslim rule but when it was conquered by Christians monoculturalism was instituted. However the buildings remain and now its multicultural identity is returning.

2 The talk I gave had been inspired by Jeanette Rhedding-Jones' writing about monoculturalism.
} 
For when do I get to say we?

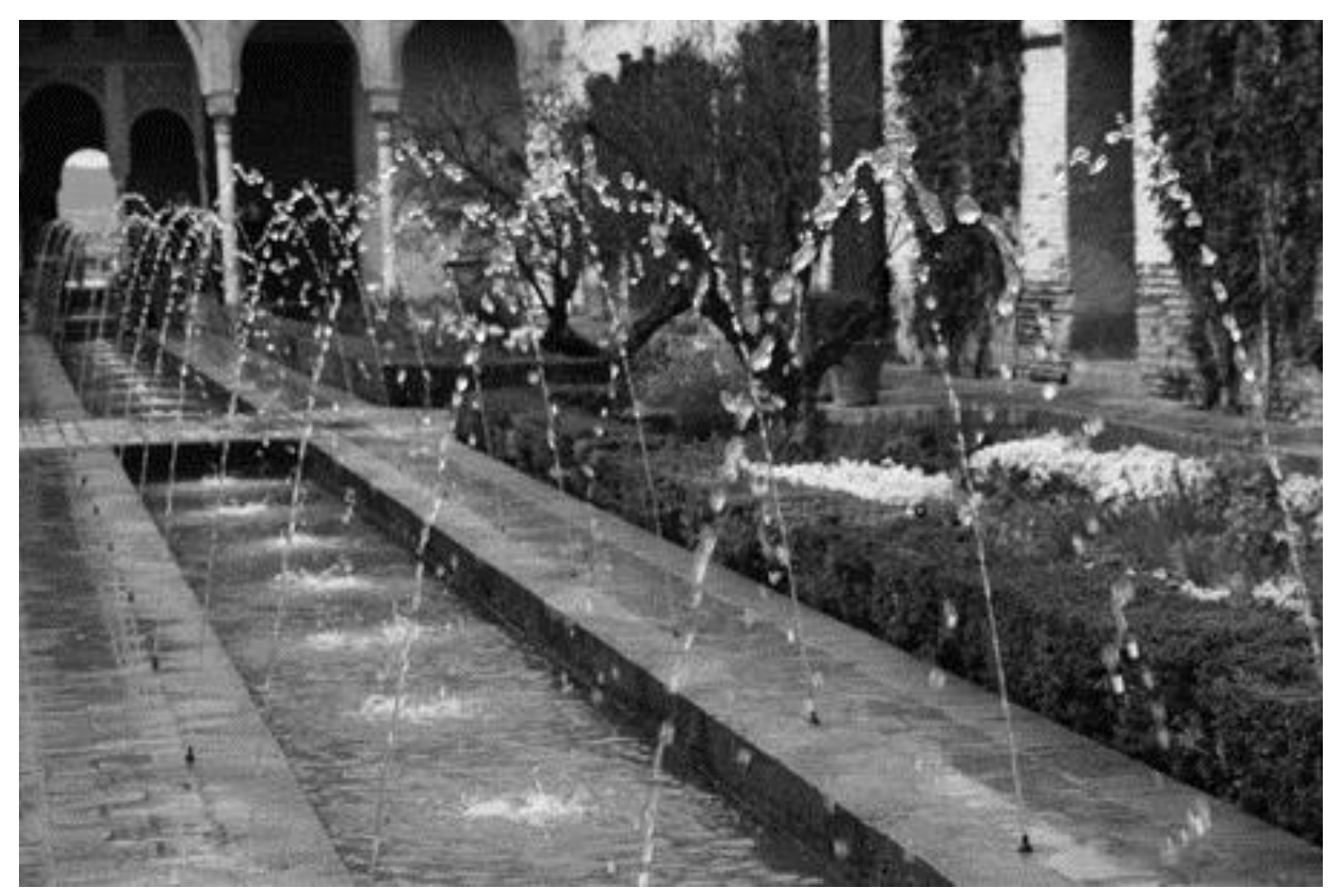

Immigration is within me, swollen and pulsating, crawling through every pore.

My eyes well with slow tears as unexpected colours fill the landscape

Or fragrances waft through the air remain tantalisingly unfamiliar.

As an immigrant, my skin and eyes hide what my tongue cannot.

Yet in the audio environment, my language is heard and esteemed

Still, when do I get to say we? 


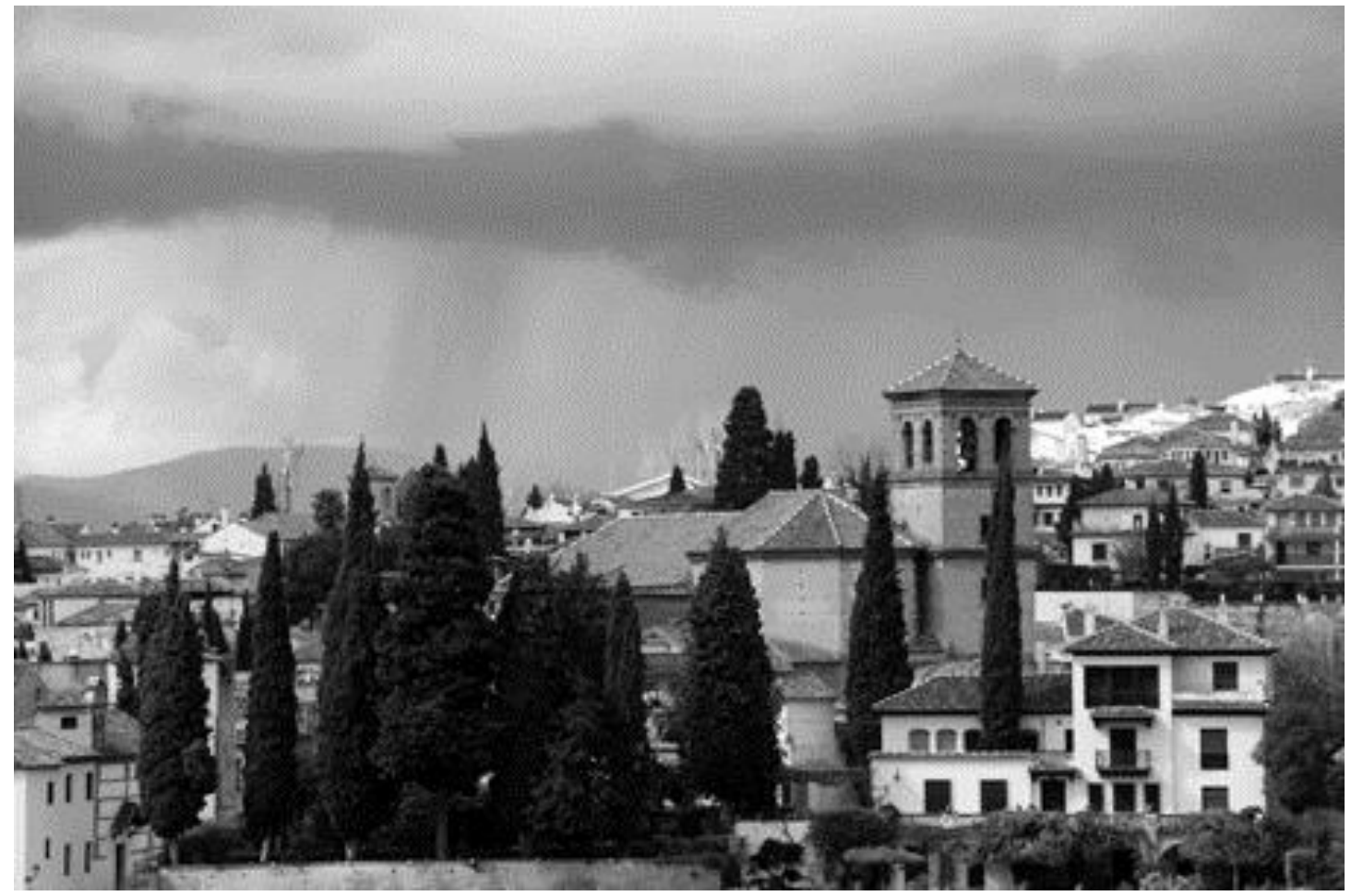

Biting reflections chew at my soul as I question who I speak for

Rights and responsibilities come unbidden with new experiences.

What choices do I make when talking about equity and diversity?

If paralysis and an inertia of uncertainty claim my voice and body,

What learning could be lost to the me and the we from gaining these insights?

Then, when do I get to say we? 


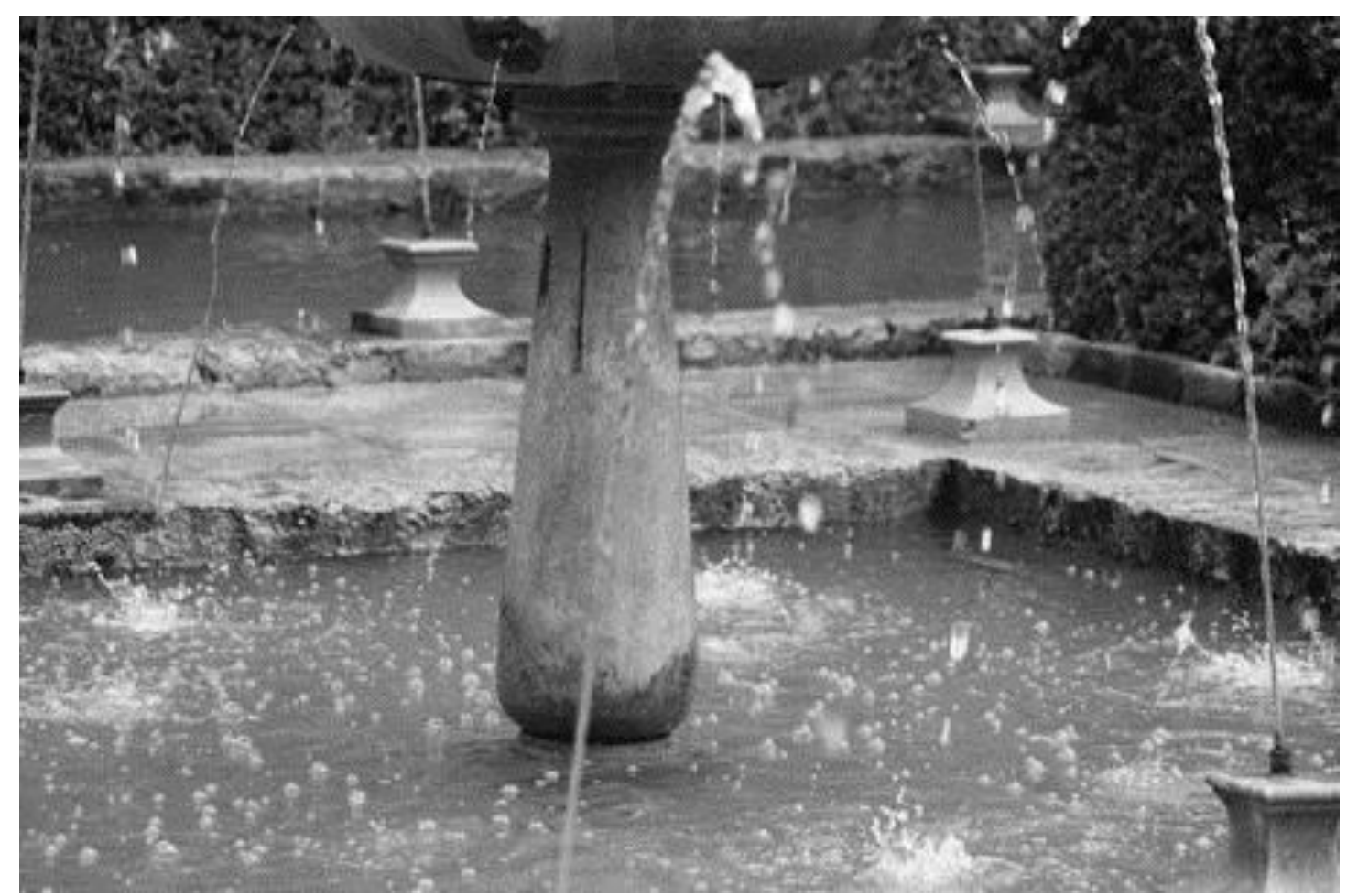

Half-learnt languages constrict me, rendering me stupid and invisible.

Conversations running through my head build sandcastles of unanswered thoughts.

Worries of far-away family dissolve and rebuild in new imaginations

Complaining is ungrateful, causing blisters of internal loneliness,

Troubling pressure bursts out loudly, negating energy and belonging

So, will I ever get to say we? 


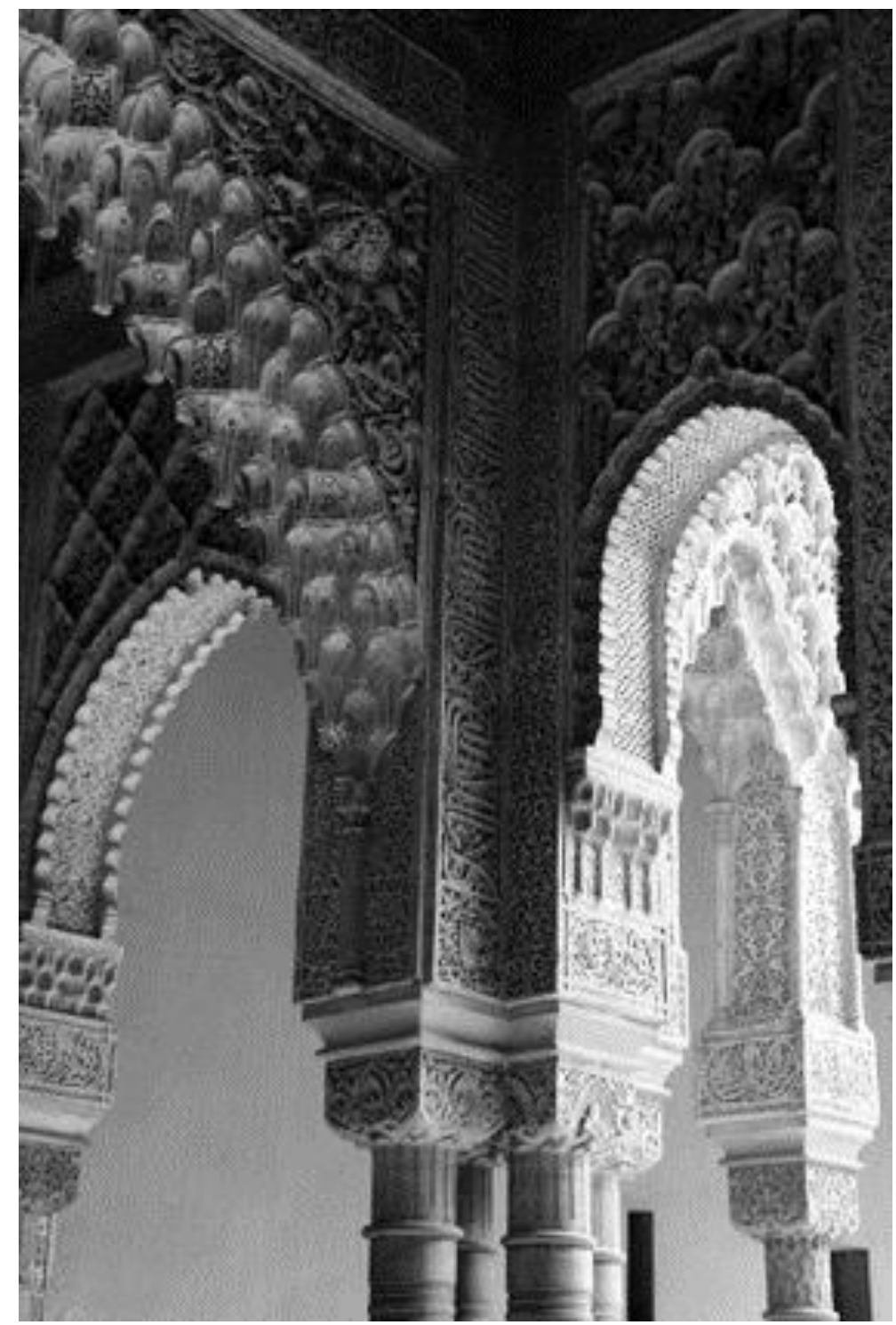

Living and working are folded and refolded into the origami of my existence,

As a transnational ${ }^{3}$, I continue to ask, "When do I get to say we?"

Issues of importance cannot be silenced and immigration cannot be denied

Treading carefully could be dangerous for both the me and the we

My role can be to find uncharted dialogue spaces and ask all:

When do we get to really say we?

\footnotetext{
${ }^{3}$ Jeanette Rhedding-Jones used this term in her writing.
} 